F O R U M

\title{
Het kind, de dokter en de dood
}

Bespiegelingen op het wetsvoorstel tot wijziging van de Wet op de lijkbezorging

Mw.mr.dr.W.L.J.M. Duijst en mr. dr.C.Das ${ }^{I}$

Reeds vele jaren wordt kindermishandeling en meer in het bijzonder kindermishandeling met dodelijke afloop gezien als een groot maatschappelijk probleem. Het meisje van Nulde, ${ }^{2}$ Savanna ${ }^{3}$ en het Maasmeisje zijn bij ons allen bekend. Elk nieuw incident is aanleiding om opnieuw na te denken over het systeem van signaleren en melden van en optreden bij kindermishandeling. De afgelopen jaren is naar aanleiding van het onderzoek van Van Kuijvenhoven e.a. veel discussie ontstaan over het 'dark number' van kindermishandeling met dodelijke afloop. ${ }^{4}$ Uit dit onderzoek bleek dat zeker veertig kinderen per jaar overleden onder op zijn minst verdachte omstandigheden, terwijl het overlijden van deze kinderen werd uitgeboekt als natuurlijk overlijden. Dit onderzoek en de daarop volgende 'Richtlijnen voor het overlijden van minderjarigen' van het adviesbureau Van Montfoort ${ }^{5}$ hebben geleid tot een tweetal voorstellen tot wijziging van de Wet op de lijkbezorging (WLB). De wetsvoorstellen hebben tot doel het 'dark number' van kindermishandeling met dodelijke afloop terug te brengen en daarmee nieuwe gevallen (bij broertjes/zusjes van het overleden kind) te voorkomen. Beide wetsvoorstellen (30 696 en 30 564) zullen worden besproken voor zover zij een verandering moeten bewerkstelligen in het handelen na het overlijden van een minderjarige. In wetsvoorstel 30 696, wordt de zogenaamde NODO-procedure (NODO: nader onderzoek naar overlijden van minderjarigen) geïntroduceerd.

In de huidige Wet op de lijkbezorging is geen aparte regeling opgenomen voor het afhandelen van het overlijden van een minderjarige. In verreweg de meeste gevallen vult de behandelend arts een verklaring van overlijden (A-verklaring) in, waarin de arts verklaart het lijk te hebben geschouwd en overtuigd te zijn van een natuurlijk overlijden (art. 7 lid I WLB). Daarnaast vult de behandelend arts de B-verklaring in voor het CBS. Is de behandelend arts niet overtuigd van een natuurlijk overlijden, dan meldt hij dit aan de gemeentelijk lijkschouwer (art. 7 lid 3 WLB). Deze laatste verricht de lijkschouw en vult naar gelang zijn bevindingen een verklaring van natuurlijk over-

I. Wilma Duijst is universitair docent strafrecht aan de Radboud Universiteit Nijmegen en forensisch geneeskundige Cees Das is hoofd van de afdeling Forensische Geneeskunde van de GGD Amsterdam. 2. Rb. Zutphen I7 januari $2003, \mathrm{LJNAF} 3006$. 3. Rb. Den Haag 2I juni 2005, LJNAT7856 en AT7853; Hof Den Haag 26 januari 2006, LJN AVo466 en AVo467; HR 9 mei 2006, LJN AV2386.

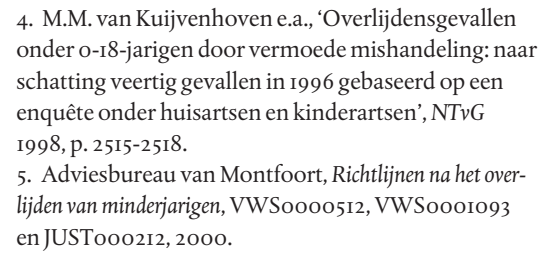

4. M.M. van Kuijvenhoven e.a., 'Overlijdensgevallen onder O-I8-jarigen door vermoede mishandeling: naar schatting veertig gevallen in 1996 gebaseerd op een enquête onder huisartsen en kinderartsen', NTvG I998, p. 2515-25I8.

5. Adviesbureau van Montfoort, Richtlijnen na het overlijden van minderjarigen, VWSoooo5I2, VWSoooI093 en JUSTooo212, 2000. 
lijden in of brengt bij een vermoeden van niet-natuurlijk overlijden verslag uit aan de officier van justitie (art. Io WLB). De officier van justitie kan in belang van het strafrechtelijk onderzoek het lichaam in beslag nemen en een gerechtelijke sectie gelasten.

Gemeentelijk lijkschouwers zijn artsen die als zodanig benoemd zijn. Dat kunnen curatief werkende artsen (meestal huisartsen) zijn, die als gemeentelijk lijkschouwer optreden of artsen die als forensisch geneeskundige zijn opgeleid. Sinds jaar en dag wordt het als een groot probleem ervaren dat niet daartoe opgeleide behandelend artsen en niet forensisch opgeleide gemeentelijk lijkschouwers de lijkschouw verrichten. ${ }^{6}$ In een onderzoek van Reijnders en Das geeft veertig procent van de (behandelend) artsen te kennen dat zij van mening zijn dat zij onvoldoende zijn toegerust om een lijkschouw te verrichten. ${ }^{7}$ Deze artsen geven aan dat zij wel regelmatig een verklaring van overlijden invullen en daarmee verklaren dat zij overtuigd zijn van een natuurlijk overlijden.

Ten einde de lacune in kennis van de behandelend artsen te dichten is recent door de KNMG de Richtlijn lijkschouw uitgebracht. ${ }^{8}$ In de richtlijn is een globale beschrijving van de items van een lijkschouw beschreven, te weten een onderzoek van de omgeving, een gesprek met de omstanders (ingeval van een kind de ouders van het overleden kind) en de schouw van het lichaam. Daarnaast is door de Ministers van Binnenlandse Zaken en Koninkrijksrelaties en Justitie in een gezamenlijke brief in november 2004 aan de Tweede Kamer toegezegd dat in een wetswijziging tot wijziging van de Wet op de lijkbezorging aan gemeentelijk lijkschouwers te stellen kwaliteitseisen zouden worden opgenomen. In het voorliggende wetsvoorstel blijkt van dit voornemen niets. ${ }^{9}$

In wetsvoorstel 30696 wordt, naast een aantal andere wijzigingen, een nieuwe procedure geïntroduceerd die moet worden gevolgd na het overlijden van een minderjarige. De procedure moet er als volgt uit gaan zien. De behandelend arts verricht de lijkschouw. De behandelend arts moet na de lijkschouw contact opnemen met de gemeentelijk lijkschouwer (art. Ioa wetsvoorstel 30696 WLB). Het wetsvoorstel zwijgt over wat de 'bevoegdheden' van de gemeentelijk lijkschouwer in dit contact zijn. Verondersteld moet worden dat de gemeentelijk lijkschouwer een advies geeft aan de behandelend arts. En aangezien in het wetsvoorstel niet wordt aangegeven wat de gevolgen van het contact tussen de behandelend arts en de gemeentelijk lijkschouwer moet zijn, is niet duidelijk wat de status is van het advies van de lijkschouwer. De behandelend arts is vrij om het advies al dan niet op te volgen.

Mocht de gemeentelijk lijkschouwer concluderen dat hij de lijkschouw moet verrichten en mocht de behandelend arts concluderen dat dit inderdaad de juiste weg is, dan kan de gemeentelijk lijkschouwer na het verrichten van de schouw tot drie conclusies komen: het overlijden is natuurlijk, de oorzaak van overlijden is onduidelijk of het overlijden is (waarschijnlijk) niet-natuurlijk.

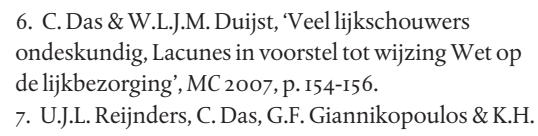

6. C. Das \& W.L.J.M. Duijst, 'Veel lijkschouwers ondeskundig, Lacunes in voorstel tot wijzing Wet op de lijkbezorging', MC 2007, p. 154-156.

7. U.J.L. Reijnders, C. Das, G.F. Giannikopoulos \& K.H.

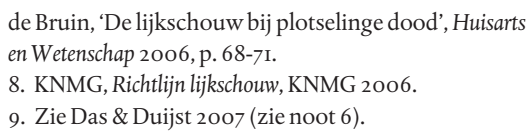


Indien de gemeentelijk lijkschouwer concludeert dat sprake is van een natuurlijk overlijden, dan vult deze de verklaring van overlijden in. Indien sprake is van een nietnatuurlijk overlijden of als daar aanwijzingen voor zijn dan meldt de gemeentelijk lijkschouwer dit aan de officier van justitie conform de bekende procedures die voor volwassenen gelden.

Kan de gemeentelijk lijkschouwer geen uitsluitsel geven over de oorzaak van overlijden dan kan hij op grond van artikel roa lid 2 wetsvoorstel tot wijziging van de Wet op de lijkbezorging zorg dragen voor een zogeheten nader onderzoek naar de doodsoorzaak, de NODO-procedure. ${ }^{\text {IO }}$ Het is uitdrukkelijk de bedoeling dat dit nader onderzoek buiten het strafrechtelijk kader valt. Het nader onderzoek bestaat uit een onderzoek door een kinderarts. Een commissie ingesteld door de ministeries van Binnenlandse Zaken en Koninkrijksrelaties en Volksgezondheid, Welzijn en Sport zal de NODO-procedure vastleggen in een protocol. In de procedure zal naast het lichamelijk onderzoek ook het maken van röntgenfoto's een plaats krijgen. Bij dit nader onderzoek kan eveneens een klinische sectie horen. Voor deze sectie is de toestemming van beide ouders van het overleden kind noodzakelijk. Niet noodzakelijk is dat de ouders ouderlijk gezag hebben; ook natuurlijke- of adoptieouders kunnen toestemming verlenen. Ontbreekt de toestemming van één of beide ouders dan kan de gemeentelijk lijkschouwer de rechtbank verzoeken om vervangende toestemming te verlenen. Uit de toelichting op het wetsvoorstel blijkt dat de vervangende toestemming zal worden gegeven door de kinderrechter. ${ }^{\text {II }}$ En daarmee wordt de NODOprocedure een civielrechtelijke procedure, die te vergelijken is met de ondertoezichtstelling, uithuisplaatsing of de ontzetting uit de ouderlijke macht. De rechtbank verleent de toestemming tenzij het belang van het achterhalen van de doodsoorzaak niet opweegt tegen de gevolgen van inwilliging van het verzoek. Uit de toelichting op het wetsvoorstel wordt niet duidelijk in welke omstandigheden dit het geval zou kunnen zijn.

Op grond van het initiatiefwetsvoorstel van Arib (wetsvoorstel 30 564) zou de behandelend arts verplicht worden om na het overlijden van een minderjarige voor de lijkschouw een forensisch geneeskundige in te schakelen (art. 7 a wetsvoorstel Arib). De bedoeling van deze verplichting is om een einde te maken aan het gebrek aan expertise waarmee de lijkschouw bij kinderen wordt verricht. De meeste artsen doen immers zelden of nooit een schouw bij een kind. ${ }^{\text {I2 }}$ Tevens zou het wetsvoorstel de verantwoordelijkheid om al dan niet een forensisch geneeskundige in te schakelen bij de behandelend arts weg moeten halen. In de toelichting op het wetsvoorstel wordt een onderscheid gemaakt tussen de schouw door de behandelend arts en de schouw

IO. Naar schatting zullen per jaar I25 kinderen voor de NODO-procedure in aanmerking komen. Zie K.H. de Bruin e.a., 'Onverklaard overlijden bij minderjarigen in de regio Amsterdam-Zaandam, 1990-2004, en schatting van het aantal dat voor nader onderzoek naar de doodsoorzaak (NODO-procedure) in aanmerking zal komen', NTvG 2007, p. 305-309. II. Kamerstukken II 2005/o6, 30 696, nr. 3, p. 2I. I2. Zie Reijnders \& Das e.a. 2006 (zie noot 7). 
door een gemeentelijk lijkschouwer. De schouw door een behandelend arts zou volgens Arib slechts een administratieve handeling zijn. De schouw door de forensisch geneeskundige zou veel uitgebreider en daarmee belastend voor de ouders zijn.

Beide wetsvoorstellen hebben gemeen dat een poging wordt gedaan om het probleem van onverklaarbaar overlijden van een minderjarige op te lossen en daardoor het dark number van kindermishandeling met dodelijke afloop terug te brengen. Het wetsvoorstel van de regering waarin de NODO-procedure is opgenomen (30 696) gaat veel minder ver dan het wetsvoorstel Arib (30 564). In beide wetsvoorstellen wordt op een zeker moment een andere arts ingeschakeld; in het voorstel van Arib wordt na elk overlijden van een minderjarige een forensisch arts ingeschakeld, in het regeringsvoorstel wordt een gemeentelijk lijkschouwer (en dat is dus niet per definitie een forensisch arts) ingeschakeld.

Een vraag die zich opdringt is de vraag naar de noodzaak van het inroepen van de hulp van een forensisch arts bij elk overlijden van een minderjarige. Uiteraard brengt de forensisch arts een speciale expertise in. Maar is die speciale expertise in alle gevallen noodzakelijk ? $^{13}$ Als argument voor het inroepen van die expertise wordt de onkunde van de behandelend arts aangevoerd. En het is inderdaad zo dat behandelend artsen een gebrek aan ervaring hebben met schouwen in het algemeen en schouwen van een minderjarige in het bijzonder. Arib geeft aan dat het schouwen van de behandelend arts een administratieve handeling is. De schouw waarover zij spreekt, feitelijk geen schouw maar slechts het invullen van de verklaring van overlijden, wordt daarmee tot norm verheven. De schouw door een behandelend arts zou echter evenzeer een beoordeling van de omgeving, een beoordeling van de anamnese en een onderzoek van het lichaam moeten zijn. Pas daarna kan de verklaring van overlijden worden afgegeven. Indien de (normale) schouw door een behandelend arts als een administratieve handeling wordt voorgesteld, dan ligt het voor de hand om de schouw door een forensisch geneeskundige (feitelijk een schouw die aan professionele norm voldoet) als heel uitgebreid en heel belastend voor de ouders te betitelen.

Blijkens het advies van de Raad van State op het wetsvoorstel is Arib niet de enige die met deze ingewikkelde materie worstelt. Ook de Raad van State is van mening dat

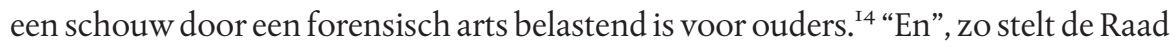
van State, "het inschakelen van de forensisch arts kan twijfel oproepen over de natuurlijke dood". ${ }^{15}$ Een raadselachtige zin. Een adequate schouw (door een behandelend arts of forensisch geneeskundige) kan immers altijd twijfel oproepen over de natuurlijke dood. Om die reden is in de wet vastgelegd dat de verklaring van overlijden pas kan worden afgegeven na de schouw. Het afgeven van deze verklaring is zeker een administratieve handeling, maar dan wel een die vooraf gegaan wordt door medisch professioneel optreden na het overlijden van een patiënt.

I3. J.J.Tiessen, 'Doodsoorzaak onbekend', MC 2007, p. $70-72$.

14. Zie ook M.C. Ploem, 'Maatregelen om meer zicht te krijgen op onverklaard overlijden bij minderjarigen', NTvG 2007, p. 284-286. 15. Kamerstukken II 2005/06, 30 564, nr. 4, p. I. 
Gezien het feit dat door verschillende partijen, al dan niet bedoeld, wordt aangegeven dat schouwen door een forensisch arts belastend is voor de ouders en aangezien het overgrote deel van de overlijdens van kinderen een natuurlijke overlijden betreft, wordt geconcludeerd dat het te bereiken doel niet meer in verhouding staat tot het in te zetten middel. Dit is een onjuiste conclusie; het feit dat een schouw door een behandelend arts op niet professionele wijze geschiedt kan niet tot gevolg hebben dat een wel professioneel uitgevoerde schouw als disproportioneel en belastend wordt betiteld. De conclusie zou eigenlijk moeten zijn dat het inroepen van een forensisch arts noodzakelijk is, omdat behandelend artsen in een groot deel van de gevallen niet bekwaam zijn om de schouw te verrichten.

Tegen het regeringsvoorstel tot wijziging van de WLB zijn onzes inziens enkele bezwaren in te brengen. In het wetsvoorstel is vastgelegd dat een behandeld arts contact moet opnemen met de gemeentelijk lijkschouwer. In dit contact maakt de arts melding van zijn bevindingen. Echter slechts de zeer recent opgeleide behandelend artsen hebben in hun opleiding onderricht gehad over het verrichten van een lijkschouw. De andere behandelend artsen doen dit naar beste vermogen. Dit betekent dat zij een lijkschouw verrichten zoals zij denken dat dat zou moeten. Dat kan betekenen dat de arts schouwt terwijl de overledene nog geheel gekleed is of dat de arts meent dat schouwen slechts betekent dat de dood moet worden vastgesteld. In sommige gevallen gebeurt zelfs dat laatste niet. Het probleem wordt nog groter als vervolgens het advies wordt gevraagd aan een gemeentelijk lijkschouwer die ook niet forensisch is opgeleid.

De NODO-procedure en het raadplegen van een gemeentelijk lijkschouwer na het overlijden van een minderjarige kennen onzes inziens het bezwaar dat de behandelend arts uiteindelijk nog steeds bepaalt wat er moet gebeuren na het overlijden van de minderjarige. De (al dan niet bekwame) behandelend arts wordt belast met de beslissing of het overlijden al dan niet natuurlijk is. Zelfs het advies dat de al dan niet in de forensische geneeskunde opgeleide gemeentelijk lijkschouwer geeft, kan de behandelend arts naast zich neer leggen.

Wij stellen voor om beide wetsvoorstellen samen te voegen en van beide voorstellen het beste deel te nemen. Het nieuwe voorstel zou er dan als volgt uitzien. De behandelend arts schouwt, indien hij zich bekwaam acht. Acht hij zich niet bekwaam, vanwege een gebrek aan ervaring in het schouwen van minderjarigen, dan moet hij een gemeentelijk lijkschouwer, die is opgeleid in de forensische geneeskunde, inschakelen om de schouw te doen. Acht de arts zich bekwaam dan moet hij na de schouw contact opnemen met de gemeentelijk lijkschouwer, die een bindend advies uitbrengt. Het advies kan zijn: het overlijden is natuurlijk, hetgeen leidt tot het invullen van een A-verklaring door de huisarts. Het advies kan zijn: er is geen duidelijkheid over de oorzaak van overlijden en de NODO-procedure treedt in werking. Ten slotte kan het advies zijn: het overlijden is mogelijk niet-natuurlijk. In dit laatste geval staakt de huisarts zijn activiteiten en neemt de gemeentelijk lijkschouwer de zaak over.

Het overleg met de gemeentelijk lijkschouwer hoeft voor de ouders niet belastend te zijn, mits goed aan de ouders wordt uitgelegd dat dit bij elk overlijden van een minderjarige verplicht is en dat de beslissing hoe het verder gaat bij de gemeentelijk lijk- 
schouwer ligt. Wij zijn ervan overtuigd dat schouwen door een gemeentelijk lijkschouwer niet belastend of bedreigend voor de ouders is mits het op professionele wijze gebeurt. Uiteraard kan een schouw leiden tot de conclusie dat een overlijden niet-natuurlijk is en mogelijk zelfs is veroorzaakt door de ouders. Feitelijk zou er hierbij geen verschil tussen de schouw door de behandelend arts en de forensisch arts moeten zijn. Het grote verschil tussen de beide artsen zit in de ervaring met nietnatuurlijk overlijden. Deze ervaring vergroot de mogelijkheid om een niet-natuurlijk overlijden te herkennen en bespreekbaar te maken. Door deze taak bij de forensisch geschoolde arts neer te leggen kan de behandelend arts zich richten op begeleiding van de ouders, die zowel bij een natuurlijk als een niet-natuurlijk overlijden zeer hard nodig zal zijn. 